\title{
Theoretical Study on the Potential Energy Surface of Decarbonylation of the Acetaldehyde by $\mathrm{Ni}^{2+}$
}

\author{
Haixia YANG \\ Department of Civil Engineering, China University of Mining and Technology Yinchuan College: \\ Yinchuan 750021, Ningxia, P R China \\ email: yhx0079@126.com
}

Keywords: density functional theory, structure, transition state, C-C activation

\begin{abstract}
Density functional theory (B3LYP) calculations has been carried out to explore the potential energy surface (PES) associated with the decarbonylation of acetaldehyde by $\mathrm{Ni}^{+2}$. The mechanism leading to the loss of $\mathrm{CH}_{4}$ and $\mathrm{CO}$ is analyzed in terms of the topology of PES. The structures and energies of the different stationary points of this PES have been obtained. Our calculations show the reaction of decarbonylation with $\mathrm{Ni}^{2+}$ takes place through four steps, that is, encounter complexation, $\mathrm{C}-\mathrm{C}$ activation, aldehyde $\mathrm{H}$-shift and nonreactive dissociation, in which the $\mathrm{H}$-shift migration process is rate-determining.
\end{abstract}

\section{Introduction}

In the past three decades, a variety of mass spectrometric techniques have been employed to investigate the reaction of transition metal ions with hydrocarbons, which is one of the most active research areas in contemporary gas-phase ion chemistry. The reactions of metal ions with organic molecules are the fundamental importance in determining the factors to the petroleum chemistry. In this field, understanding the mechanisms of $\mathrm{C}-\mathrm{C}$ and $\mathrm{C}-\mathrm{H}$ activation of decarbonylation by transition metal ions are of particular interest. Researchers made a significant efforts the concerning these aspects ${ }^{[1-7]}$. Many experimental techniques have been used to study the mechanism of the bond activation of decarbonylation by transition metal ions. From these studies, we have seen a variety of fundamental experimental and mechanistic information about decarbonylation by transition metal ions. Sonnenfroh has reported the crossed beam studies of energy and angular distributions of the decarbonylation products of acetaldehyde with metal ions (reaction 1), which is a dominant process at low reaction energies.

$$
\mathrm{M}^{+}+\mathrm{CH}_{3} \mathrm{CHO} \rightarrow \mathrm{CH}_{4}+\mathrm{MCO}^{+}
$$

However, the reaction mechanism isn't clear, it is not sure that the reaction takes place via $\mathrm{C}-\mathrm{C}$ and $\mathrm{C}-\mathrm{H}$ activation. The density functional theory offers quantum chemical calculations in principle of obtaining information on the structure and energy details of the potential energy surfaces (PES) for the reaction. This method has been widely used to calculate the electronic structure on systems containing transition metals, which gets reasonable results with accuracy sufficient for describing open-shell metal systems. In order to study the theoretical investigation on the $\mathrm{M}^{+}$-assisted decarbonylation of acetaldehyde, $\mathrm{Ni}^{2+}$ was used as representative of first-row transition metal ions, The structures of various species and the energies of key reaction was computed using DFT method (B3LYP). In this paper. The results are to be analyzed in light of the available theoretical information to characterize the minima and saddle points relevant to the $\mathrm{C}-\mathrm{H}$ or $\mathrm{C}-\mathrm{C}$ activation.

\section{Computational method}

Quantum-mechanics calculations were performed with the Gaussian 03 program. All species were calculated using density functional theory with the B3LYP method ${ }^{[8]}$ using the $6-31+\mathrm{G}^{* *}$ basis set in $\mathrm{C}, \mathrm{H}, \mathrm{O}$ atoms and Lanl2dz basis sets in $\mathrm{Ni}$ atom. which is flexible enough to give a good account of longer range ion-ligand interactions and is also large enough to generally reduce the basis set superposition error (BSSE) to less than the errors inherent in the method, so that BSSE 
corrections was unnecessary. Each stationary point was characterized by the frequency analysis (minimum with zero; transition state with one imaginary frequency). In order to gain an insight into the energetic requirements for $\mathrm{Ni}^{2+}$ reacting with acetaldehyde, intrinsic reaction coordinate (IRC) calculations were performed to follow the reaction pathways.

\section{Results and discussion}

In the following sections, the theoretical results for various intermediates, transition state, and products involved in decarbonylation of $\mathrm{Ni}^{2+}$ will be presented. And then, the mechanistic details for each reaction will be discussed. It indicated the ability of basis set to describe the features of the PES of $\left[\mathrm{Ni}^{2+}, \mathrm{O}, \mathrm{C} 2, \mathrm{H} 4\right]$. For convenience, all of the results were obtained at $6-31+\mathrm{G}^{* *}$ basis sets in $\mathrm{C}, \mathrm{H}, \mathrm{O}$ atoms and Lanl2dz basis sets in $\mathrm{Ni}$ atom level. The optimized geometries and structural parameters for the stationary point along the decarbonylation pathway are shown in Fig.1, the calculated covalent bond orders for the decarbonylation are tabulated in Table.1, the relevant energies and the sketch of the PES is given in Fig.2.

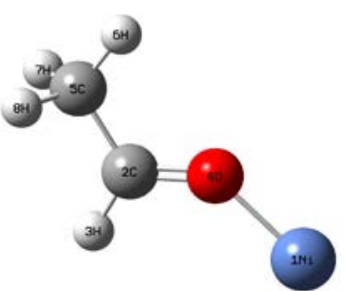

M1

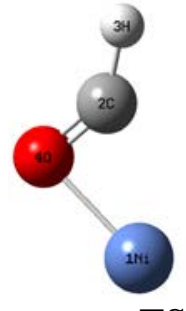

TS1

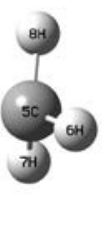

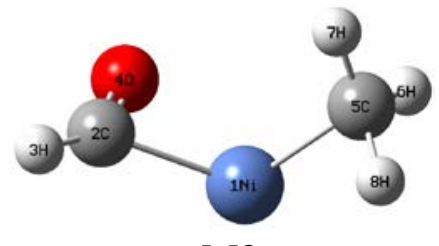

M2

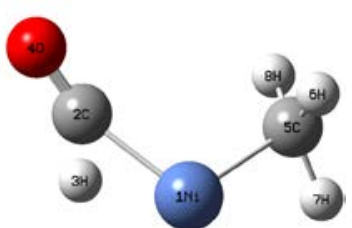

TS2

Figure. 1 the structures of the decarbonylation reaction of $\mathrm{CH}_{3} \mathrm{CHO}$ with $\mathrm{Ni}^{+2}$

From the Fig. 1, we know the potential energy surface is the triplet surface of $\left[\mathrm{Ni}^{2+}, \mathrm{O}, \mathrm{C} 2, \mathrm{H} 4\right]$, there were three minima (noted as M1, M2, and products, respectively) and two first-order saddle point (noted as TS1 and TS2, respectively) the decarbonylation coordinate on the PES in the Fig. 2. The reaction proceeds through four elementary steps, i.e., encounter complexation, $\mathrm{C}-\mathrm{C}$ activation, $\mathrm{H}$-shift and nonreactive dissociation, and the third step of the process constitutes the rate-determining step. As shown in Fig. 2, the reaction starts with the association of $\mathrm{Ni}^{2+}$ with acetaldehyde leading to encounter complex M1, which is the first step. M1 is the first the intermediates, the ${ }^{1} \mathrm{Ni}^{-}{ }^{4} \mathrm{O}$ distance is $1.803 \AA$, at the same time, the $\mathrm{Ni}^{2+}-\mathrm{O}$ binding energies is 48.3 $\mathrm{kcal} / \mathrm{mol}$, which is less than the sum of $\mathrm{Ni}^{2+}$ and $\mathrm{CH}_{3} \mathrm{CHO}$. It is the result of oxygen polarizing charge toward $\mathrm{Ni}^{2+}$. The overall symmetries of the encounter complexes are nearly Cs with the symmetry plane defined by ${ }^{1} \mathrm{Ni}-{ }^{4} \mathrm{O}-{ }^{2} \mathrm{C}-{ }^{5} \mathrm{C}(\mathrm{M} 1)$.

Once complex $\mathrm{M} 1$ is formed, the ${ }^{2} \mathrm{C}-{ }^{5} \mathrm{C}$ bond could be activated by the metal ion. This process results in intermediate $\mathrm{M} 2$, in which the activated bond has been ruptured as reflected by the very large bond length $\left(3.185 \mathrm{~A}^{\circ}\right)$. The concomitant association of $\mathrm{Ni}^{2+}$ with the acetaldehyde by an overall Cs symmetry with the symmetry plane defined by ${ }^{1} \mathrm{Ni}-{ }^{4} \mathrm{O}-{ }^{2} \mathrm{C}-{ }^{5} \mathrm{C}$, as well as the ${ }^{2} \mathrm{C}-{ }^{1} \mathrm{Ni}-{ }^{5} \mathrm{C}$ angle of $108.6^{\circ}$ is due to the approximate sd hybridization at $\mathrm{Ni}^{2+}$. Energetically, energy is lower than TS1 $10.5 \mathrm{kcal} / \mathrm{mol}$. From the structure, it can be seen that $\mathrm{Ni}^{2+}$ ion inserts the ${ }^{2} \mathrm{C}-{ }^{5} \mathrm{C}$ band. M2 is the Cs symmetry, the symmetry surface is $\mathrm{O}^{2} \mathrm{C}-\mathrm{Ni}^{-}{ }^{5} \mathrm{C}$. The direct break of $\left(\mathrm{H}_{3} \mathrm{C}\right) \mathrm{Ni}^{2+}-\mathrm{CHO}$ bond results $\mathrm{Ni}^{+2} \mathrm{CH}_{3}$ and $\mathrm{CHO}$. The ${ }^{1} \mathrm{Ni}^{-}{ }^{6} \mathrm{H} 、{ }^{1} \mathrm{Ni}-{ }^{5} \mathrm{C} 、{ }^{1} \mathrm{Ni}^{-}{ }^{2} \mathrm{C}$ and ${ }^{1} \mathrm{Ni}-{ }^{4} \mathrm{O}$ distances are $2.287 \AA, 1.971 \AA$, $2.003 \AA$ and $1.951 \AA$, it shows that the atom Ni still interacts with all these atoms, however ${ }^{2} \mathrm{C}-{ }^{5} \mathrm{C}$ distance is $3.185 \AA$, it shows ${ }^{2} \mathrm{C}-{ }^{5} \mathrm{C}$ bond has been broken. $\mathrm{M} 2$ can be rearranged to an H-shifted species $\mathrm{H}_{4} \mathrm{C}-\mathrm{Ni}^{2+}$ (CO) (p), which can be a direct precursor of the decarbonylation products $\left(\mathrm{CH}_{4}\right.$ and $\left.\mathrm{Ni}^{2+}(\mathrm{CO})\right)$. 
Table 1 the calculated covalent bond orders for the decarbonylation with $\mathrm{Ni}^{+2}$

\begin{tabular}{ccccccc}
\hline & ${ }^{1} \mathrm{Ni}-{ }^{4} \mathrm{O}$ & ${ }^{2} \mathrm{C}-{ }^{5} \mathrm{C}$ & ${ }^{4} \mathrm{O}-2 \mathrm{C}$ & ${ }^{1} \mathrm{Ni}-{ }^{2} \mathrm{C}$ & ${ }^{1} \mathrm{Ni}-{ }^{5} \mathrm{C}$ & ${ }^{1} \mathrm{Ni}-{ }^{6} \mathrm{H}$ \\
\hline M1 & 1.803 & 1.469 & 1.261 & & & \\
TS1 & 1.893 & 2.328 & 1.26 & 2.131 & 2.041 & 2.362 \\
M2 & 1.951 & 3.185 & 1.259 & 2.003 & 1.971 & 2.287 \\
TS2 & 1.861 & 3.007 & 1.261 & 1.872 & 1.982 & 2.264 \\
\hline
\end{tabular}

M1and M2 are connected through the multicenter transition state (TS1), which is formed by the metal ion insertion into the $\mathrm{C}-\mathrm{C}$ bond of acetaldehyde. A striking feature of the transition state is $\mathrm{Ni}^{2+}$ binds concomitantly to the $\mathrm{O}, \mathrm{H}$ and $\mathrm{C}$ atom, both the carbon atoms of the breaking $\mathrm{C}-\mathrm{C}$ bond, and one of the $\mathrm{H}$ atoms of the migrating methyl group. The ${ }^{1} \mathrm{Ni}-{ }^{6} \mathrm{H} 、{ }^{1} \mathrm{Ni}-{ }^{5} \mathrm{C} 、{ }^{1} \mathrm{Ni}-{ }^{2} \mathrm{C}$ and ${ }^{1} \mathrm{Ni}-{ }^{4} \mathrm{O}$ distances are $2.362 \AA, 2.041 \AA, 2.131 \AA$ and $1.89 \AA$, and the ${ }^{2} \mathrm{C}-\mathrm{Ni}-{ }^{5} \mathrm{C}$ angle o is $98.7^{\circ}$, which indicate the $\mathrm{Ni}^{2+}$ center interacts with these atoms closely. Although the transition state TSl is the first saddle between the intermediate M1 and M2, the bond distance is closed to the M2, so it is the late transition state of potential energy surface, from the bond distance and the angle, it can be seen that TS1 has an overall Cs symmetry with the symmetry plane defined by ${ }^{1} \mathrm{Ni}-{ }^{4} \mathrm{O}-{ }^{2} \mathrm{C}-{ }^{5} \mathrm{C}$, This transition state is expected to be stabilized to some extent by an agnostic interaction between the 2C - $\mathrm{H} 1$ bond and the $\mathrm{Ni}^{2+}$ center as evident by the stretched bond length of ${ }^{2} \mathrm{C}-{ }^{5} \mathrm{C}$, As a consequence, it lies below the entrance channel by $11.2 \mathrm{kcal} / \mathrm{mol}$, which translates into an energy barrier of 37.1 $\mathrm{kcal} / \mathrm{mol}$ with respect to $\mathrm{M} 1$.

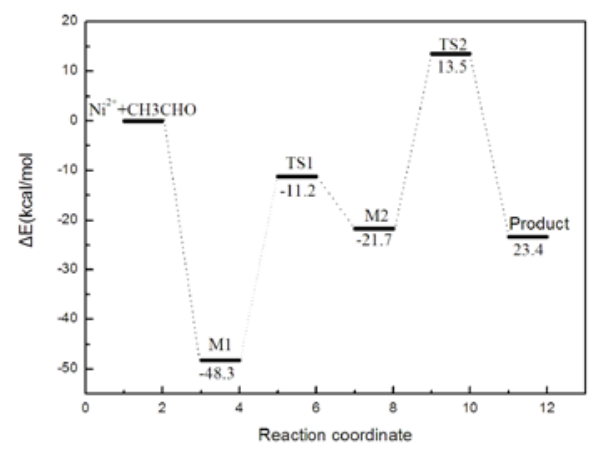

Figure. 2 the diagram of relative energies along the channels for the decarbonylation

Transition state TS2 connects M2 and products, which was carefully confirmed by IRC calculations. Along the decarbonylation coordinate, complex TS2 can be rearranged to an $\mathrm{H}$-shifted species $\mathrm{H}_{4} \mathrm{C}-\mathrm{Ni}^{2+}(\mathrm{CO})$, which can be a direct precursor of the decarbonylation products (CH4and $\mathrm{Ni}^{2+}(\mathrm{CO})$ ). It can be seen that complex 3has no symmetry elements. In contrast to the traditional suggestion that the rate-determining step is initial C-C insertion. TS2 is found to be the most demanding point along the whole $\mathrm{CH}_{4}$ and $\mathrm{CO}$ elimination pathway, the energy is higher 24.7 $\mathrm{kcal} / \mathrm{mol}$ than the initial $\mathrm{C}-\mathrm{C}$ activation transition state and $13.5 \mathrm{kcal} / \mathrm{mol}$ than the separated reactants. Therefore, on the basis of the B3LYP calculations, TS2 is in fact the rate-determining tight transition state of the $\mathrm{CH}_{4}$ and $\mathrm{CO}$ elimination. Structurally, the ${ }^{2} \mathrm{C}-{ }^{5} \mathrm{C}$ bond distance and ${ }^{2} \mathrm{C}-{ }^{6} \mathrm{H}$ distance elongated, suggesting it is a saddle point that connects products to either M2 via $\mathrm{Ni}^{+2}$ insertion into $\mathrm{C}-\mathrm{C}$ bond. The ${ }^{2} \mathrm{C}-{ }^{5} \mathrm{C}$ bond distance is $3.007 \AA$, it shows the ${ }^{2} \mathrm{C}-{ }^{5} \mathrm{C}$ bond have been broken. A key mechanistic question is whether the TS2 lies well above the initial bond insertion one TS1 or vice versa. All our attempts to locate such a minimum as $\mathrm{H}\left(\mathrm{CH}_{3}\right) \mathrm{Ni}^{2+}$ (CO) on the $\left[\mathrm{Ni}^{2+}, \mathrm{O}, \mathrm{C} 2, \mathrm{H} 4\right]$ lead instead to $\mathrm{M} 2$ or product, suggesting that only species product can be the precursor of products $\mathrm{CH} 4$ and $\mathrm{Ni}^{2+}$ (CO).

It is very clear that the reaction occurs through $\mathrm{Ni}^{2+}$ insertion into $\mathrm{C}-\mathrm{C}$ bond followed by an aldehyde $\mathrm{H}$-shift and then a nonreactive-dissociation of the $\mathrm{H}_{4} \mathrm{C}-\mathrm{Ni}^{2+}(\mathrm{CO})$ bond. The $\mathrm{H}$-shift is the rate-determining step in the reaction, the energy barrier is $13.5 \mathrm{kcal} / \mathrm{mol}$ with respect to the 
separated reactants. It was nicely explained by invoking the initial $\mathrm{C}-\mathrm{H}$ insertion transition state (TSCH) as the rate-determining barrier to both $\mathrm{H}_{2}$ and $\mathrm{CH}_{4}$ elimination, it also verified the accuracy of the computational strategy employed.

\section{Conclusion}

In this paper, we provided new insight into the reaction of $\mathrm{Ni}^{2+}$ with acetaldehyde using DFT The theory. The $\mathrm{CH}_{4}$ and $\mathrm{CO}$ loss by $\mathrm{Ni}^{2+}$ proceeds through four elementary steps, i.e., encounter complexation, $\mathrm{C}-\mathrm{C}$ activation, $\mathrm{H}$-shift and nonreactive dissociation, and the third step of the process constitutes the rate-determining step. The stable precursor of the decarbonylation products $\mathrm{CH}_{4}$ and $\mathrm{Ni}^{2+}(\mathrm{CO})$ has a structure of $\left(\mathrm{CH}_{4}\right) \mathrm{Ni}^{2+}(\mathrm{CO})$ rather than $\left.\left(\mathrm{CH}_{3}\right) \mathrm{H} \mathrm{Ni}^{2+} \mathrm{CO}\right)$. The decarbonylation of $\mathrm{CH}_{3} \mathrm{CHO}$ with $\mathrm{Ni}^{+2}$ follows $\mathrm{C}-\mathrm{C}$ activation rather than aldehyde $\mathrm{C}-\mathrm{H}$ activation.

\section{Acknowledgements}

This work was supported by Ningxia Colleges and Universities Scientific Research Project (No. NGY2014170).

\section{References}

[1] Senthilnathan V P, Stein S E. Mechanisms of condensation of biaryl hydrocarbons [J]. Organic Chemistry, 198853 (13) 3000-3007.

[2] Corderman R R, Beauchamp J L. Ion Cyclotron Reaonance Investigation of the Decarbonylation of Aldehydes by (.eta.5-cyclopentadienyl) Nickel(1+) [J] J.Am.Chem.Soc. 1976 (98) 5700-5702.

[3] Clark P D, Hyne J B, Tyrer J D. Chemistry of organo sulfur compound type occurring in heavy oil sands: 4. The high-temperature reaction of hiophene and tetrahydro-thiophene with aqueous solution of aluminium and first row transition-metal cations[J]. Fuels, 1987 66(10) 1353-1357.

[4] Ovalles C, Filgueiras E, Morales A, et al. Use of a dispersed iron catalyst for upgrading extra-heavy crude oil using methane as source of hydrogen[J]. Fuel, 2003,82(8): 887 -892.

[5] Ignasiak T M, Strause O P. Reaction of Athabasca asphaltene with tetralin[J]. Fuel 197857 (10) 617-621.

[6] Vallejos C, Vasquez T, Process for the downhole upgrading of extra heavy crude oil. US, 5891829[P], 1999-04-06.

[7] Tayfun B. Evaluation of EOR methods for heavy-oil recovery in naturally fractured reservoirs[J]. Journal of Petroleum Science and Engineering, 2003, 37(1): 25 37.

[8] M.J.Frisch, G.W.Trucks, et al. Gaussian 03 (revision B.05). Pittsburgh, PA: Gaussian,Inc.,2003. 